\title{
Influence of temperature on gas solubility in thermally rearranged (TR) polymers
}

\author{
Kevin A. Stevens ${ }^{\mathrm{a}}$, Zachary P. Smith ${ }^{\mathrm{b}}$, Kristofer L. Gleason ${ }^{\mathrm{a}}$, Michele Galizia ${ }^{\mathrm{a}}$, \\ Donald R. Paul ${ }^{\mathrm{a}}$, and Benny D. Freeman ${ }^{\mathrm{a}, *}$
}

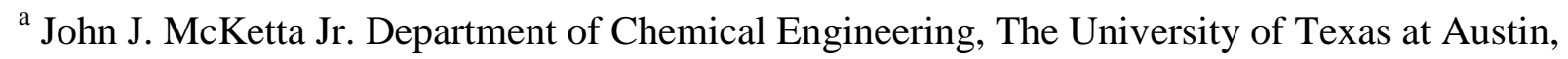
200 E. Dean Keeton Street, Austin, TX 78712, Center for Energy and Environmental Resources, 10100 Burnet Rd., Building 133 (CEER), Austin, TX 78758, USA

${ }^{\mathrm{b}}$ Department of Chemical Engineering, Massachusetts Institute of Technology, 25 Ames Street, Cambridge, MA 02142, USA

\section{Submission to Journal of Membrane Science}

*Corresponding Author: Email: freeman@che.utexas.edu Tel: 1-512-232-2803 


\begin{abstract}
Thermally rearranged (TR) polymers have been the subject of many fundamental studies, but the effect of TR conversion on temperature-dependent transport properties is largely unexplored. Sorption isotherms for $\mathrm{N}_{2}, \mathrm{CH}_{4}$, and $\mathrm{CO}_{2}$ in $\mathrm{HAB}-6 \mathrm{FDA}$ polyimide and its TR analogs were measured at temperatures ranging from $-10{ }^{\circ} \mathrm{C}$ to $50{ }^{\circ} \mathrm{C}$ and pressures up to 27 atm. Solubilities increase with decreasing temperature for each gas and sample tested. At low TR conversions, the sorption process initially becomes less exothermic. However, enthalpies of sorption do not significantly change with TR conversion after the initial stages of rearrangement. Enthalpies of sorption in TR polymers are qualitatively similar to those of other high free volume materials. Solubility selectivity for $\mathrm{CO}_{2} / \mathrm{CH}_{4}$ at 10 atm did not change with temperature due to similar enthalpies of sorption for $\mathrm{CO}_{2}$ and $\mathrm{CH}_{4}$. Sorption data were fit to the dual mode model at different temperatures, and model parameters were correlated with polymer and penetrant properties.
\end{abstract}

Keywords: TR polymers, temperature dependence, gas solubility, enthalpy of sorption, dual mode model 


\section{Graphical Abstract}
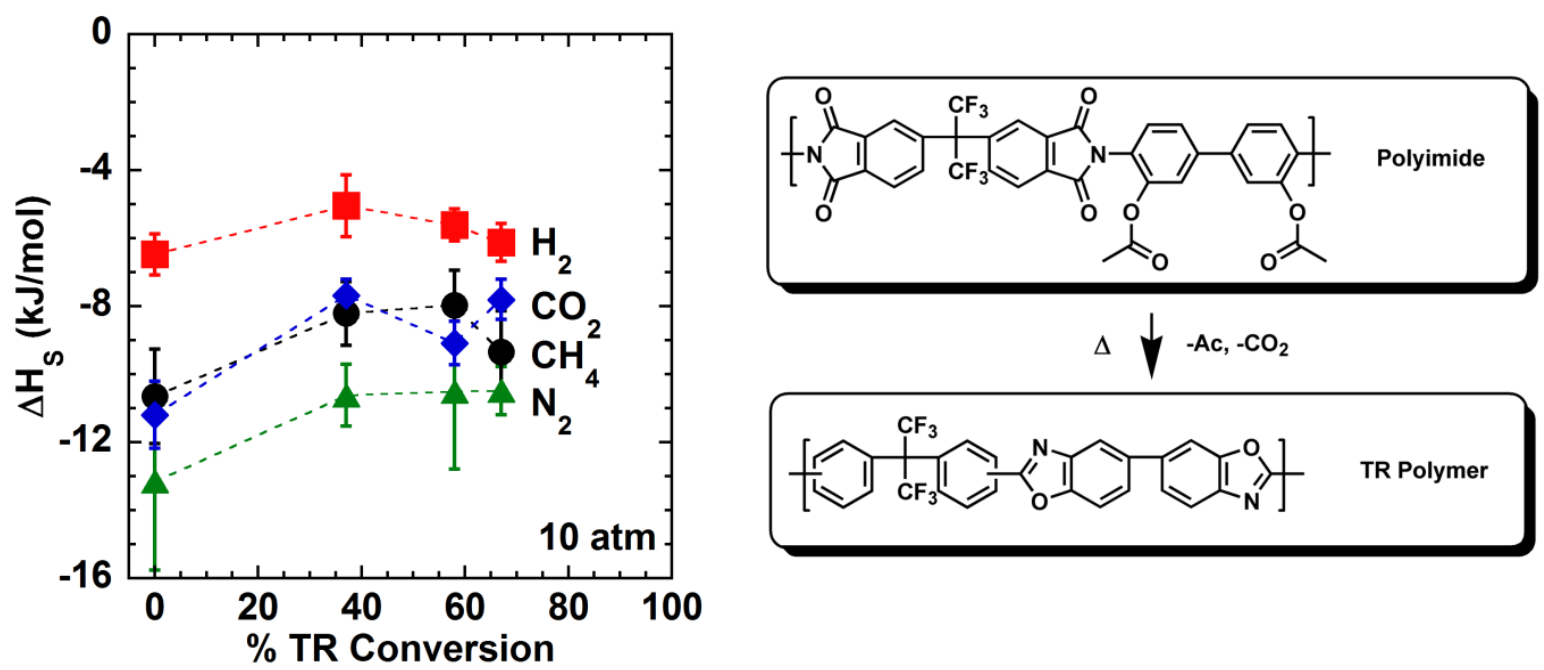


\section{Introduction}

Transport properties of polymers are typically reported near ambient temperature (e.g., 25 to $35^{\circ} \mathrm{C}$ ). However, many membrane separations are performed at either higher or lower temperatures [1-4]. For example, in natural gas separations, the expansion of $\mathrm{CO}_{2}$ permeating through a membrane results in Joule-Thomson cooling [1]. Additionally, $\mathrm{H}_{2} / \mathrm{CO}_{2}$ separation at the exit of a water gas shift reactor is being considered using membranes that operate near 200 ${ }^{\circ} \mathrm{C}$ [4]. Many transport property studies include only permeability measurements near ambient conditions, thereby limiting the availability of data necessary to understand, at a fundamental level, membrane performance at temperatures far from ambient conditions. The study of temperature dependence is critical to develop improved membranes at temperatures far from ambient.

The temperature dependence of solubility has been previously examined in detail for a number of polymers. Koros and Paul reported $\mathrm{CO}_{2}$ sorption in poly(ethylene terephthalate) (PET) from 25 to $115^{\circ} \mathrm{C}$ [5]. The effects of temperature on solubility and dual mode parameters above and below the glass transition temperature of PET were elucidated [5]. As temperature increased, all dual mode parameters decreased. Beyond the glass transition temperature, the Langmuir contribution to solubility vanished consistent with the lack of non-equilibrium free volume above the glass transition temperature [5]. Costello et al. studied transport properties of meta/para-isomers of hexafluoroisopropylidene-containing polyimides at ambient and higher temperatures [6]. The para-isomer was further below its glass transition temperature than the meta analog and had a higher fractional free volume, resulting in higher Langmuir sorption capacities than the para isomer. Solubility for $\mathrm{He}, \mathrm{N}_{2}, \mathrm{O}_{2}, \mathrm{CH}_{4}$, and $\mathrm{CO}_{2}$ decreased with increasing temperature [6]. Merkel et al. studied the solubility and permeability of light gases, 
hydrocarbons, and fluorocarbons in a glassy random copolymer of polytetrafluoroethylene and $\operatorname{poly}\left(2,2-\right.$ bis(trifluoromethyl)-4,5-difluoro-1,3-dioxole) (AF2400 ${ }^{\circledR}$ ) from 25 to $45{ }^{\circ} \mathrm{C}$ [7]. The transport properties of AF $2400^{\circledR}$ were influenced strongly by its high free volume, which made enthalpies of sorption more exothermic than in lower free volume polymers and lowered activation energies of diffusion, resulting in low activation energies of permeation [7].

Thermally rearranged (TR) polymers are aromatic polymers with interconnected heterocyclic rings derived from a post-processing thermal treatment (i.e., thermal rearrangement) of polyimides with ortho-functional groups [8]. Depending on the ortho-position group, TR polymers can take the form of polybenzimidazoles, polybenzothiazoles, and polybenzoxazoles [8-10]. Polybenzoxazoles are often insoluble in common organic solvents [11] and resistant to aggressive chemical environments [11].

The literature on temperature dependence of TR polymer transport properties is limited. Han et al. focused on polybenzimidazoles (PBIs) formed via a thermal rearrangement process [9]. The resulting TR-PBIs exhibited very high permeabilities of $\mathrm{CO}_{2}, \mathrm{CH}_{4}, \mathrm{O}_{2}, \mathrm{~N}_{2}$, and $\mathrm{H}_{2}$ with good selectivities near ambient conditions, but selectivities decreased with increasing temperature. Han also examined the temperature dependence of transport of $\mathrm{H}_{2}$ and $\mathrm{CO}_{2}$ in TR$\beta$-polymers formed from poly(hydroxyamide) precursors [12]. $\mathrm{H}_{2}$ and $\mathrm{CO}_{2}$ permeabilities increased with temperature, but the increase in $\mathrm{H}_{2}$ permeability was larger than the increase in $\mathrm{CO}_{2}$ permeability because of the significant decrease in $\mathrm{CO}_{2}$ sorption with increasing temperature.

Kim et al. examined the temperature dependence of transport of a series of light gases in TR- $\beta$-PBOs and found that permeabilities and diffusivities increased with increasing temperature while solubility decreased [13]. Additionally, the lower permeabilities observed by Kim 
correlated with the lower free volume in TR- $\beta$-polymers compared to polyimide-based PBOs [13]. Smith et al. studied the temperature-dependence of hydrogen sorption in several polymers, including TR polymers [14]. While the solubility of $\mathrm{H}_{2}$ in TR polymers increased with TR conversion, enthalpies of sorption did not change significantly [14].

In this study, the temperature-dependent solubilities of $\mathrm{N}_{2}, \mathrm{CH}_{4}$, and $\mathrm{CO}_{2}$ in $\mathrm{HAB}-6 \mathrm{FDA}$ polyimide and its TR polymer analogs are presented together with prior $\mathrm{H}_{2}$ data [14]. Solubility increases with decreasing temperature for all gases. Solubilities and enthalpies of sorption are presented at 10 atm. While solubility increases with increasing TR conversion, enthalpies of sorption initially decrease in magnitude with initial TR conversion and then do not substantially change with further TR conversion. $\mathrm{CO}_{2} / \mathrm{CH}_{4}$ solubility selectivity at 10 atm was independent of temperature for all samples due to similar enthalpies of sorption between $\mathrm{CO}_{2}$ and $\mathrm{CH}_{4}$. Isosteric enthalpies of sorption were determined as a function of penetrant concentration. Finally, solubility isotherms were interpreted in the framework of the dual mode model.

\section{Background}

The gas solubility coefficient, $S$, is the concentration of gas sorbed into a polymer, $C$, at a specific pressure, $p$, and temperature (i.e., $S=C / p$ ). The temperature dependence of solubility can be modeled using a van't Hoff relation [15]:

$$
S=S_{0} e^{\frac{-\Delta H_{S}}{R T}}
$$

Eq. 1

where $S$ is the solubility coefficient $\left(\mathrm{cm}^{3}(\mathrm{STP}) /\left(\mathrm{cm}^{3}\right.\right.$ polymer atm) $), \Delta H_{S}$ is the enthalpy of sorption $(\mathrm{kJ} / \mathrm{mol}), R$ is the ideal gas constant, $T$ is temperature $(\mathrm{K})$, and $S_{0}$ is an exponential 
pre-factor associated with entropic effects of sorption. Solubility selectivity can be expressed as a function of temperature according to a van't Hoff relationship:

$$
\alpha_{S_{A} / S_{B}}=\frac{S_{A}}{S_{B}}=\frac{S_{0, A}}{S_{0, B}} e^{\frac{-1}{R T}\left(\Delta H_{S, A}-\Delta H_{S, B}\right)}
$$

where the variables are as defined in Equation 1.

$S$ usually increases exponentially with gas critical temperature (i.e., $\ln S=\ln S_{0}+a_{c} T_{c}$ ) $[16,17]$. The slope of this correlation, $a_{c}$, is almost always independent of polymer structure and morphology, and $a_{c}$ is typically in the range of $0.015-0.019 \mathrm{~K}^{-1}[16]$ for a range of sorbents including liquids, rubbery polymers, and glassy polymers.

The dual mode model [15] is often used to describe gas sorption in glassy polymers. The gas concentration in the polymer is expressed as follows:

$$
C=k_{D} p+C_{H}^{\prime} \frac{b p}{1+b p}
$$

where $C\left(\mathrm{~cm}^{3}(\mathrm{STP}) /\left(\mathrm{cm}^{3}\right.\right.$ polymer $\left.)\right)$ is the total gas concentration in the polymer, $k_{D}\left(\mathrm{~cm}^{3}\right.$ (STP) $/\left(\mathrm{cm}^{3}\right.$ polymer atm) $)$ is the Henry's law sorption coefficient, $C_{H}^{\prime}\left(\mathrm{cm}^{3}(\mathrm{STP}) /\left(\mathrm{cm}^{3}\right.\right.$ polymer) ) is the Langmuir capacity parameter, $b\left(\mathrm{~atm}^{-1}\right)$ is the Langmuir affinity constant, and $p$ is the external penetrant pressure (atm) [18].

The temperature dependence of $k_{D}$ and $b$ are described using Arrhenius-van't Hoff relationships [15, 18]:

$$
\begin{gathered}
k_{D}=k_{D 0} e^{\frac{-\Delta H_{D}}{R T}} \\
b=b_{0} e^{\frac{-\Delta H_{b}}{R T}}
\end{gathered}
$$


where $\Delta H_{D}$ and $\Delta H_{b}$ are the Henry's and Langmuir modes enthalpies of sorption, respectively. $C_{H}^{\prime}$ does not follow the same trend with temperature as $k_{D}$ and $b$ [18]. Excess free volume diminishes in the polymer matrix as temperature increases towards the glass transition temperature [17], so $C_{H}^{\prime}$ decreases as the glass transition temperature is approached and vanishes at the glass transition temperature [5, 19].

The three dual mode parameters are typically determined by non-linear regression of $C$ vs. $p$ at different temperatures (or $S$ vs. $p$ and $T$ ). In the limit of vanishing pressure, the dual mode equation for $S$ becomes:

$$
\lim _{p \rightarrow 0} S=S^{\text {inf }}=k_{D}+C_{H}^{\prime} b
$$

where $S^{\text {inf }}$ is the infinite-dilution solubility coefficient.

The concentration dependence of the enthalpy of sorption is given by [18]:

$$
\left[\frac{\partial \ln p}{\partial(1 / T)}\right]_{C}=\frac{\Delta H_{I}}{z R}
$$

where $\Delta H_{I}$ is the isosteric heat of sorption, $p$ is the pressure associated with a given penetrant concentration, $C$, in the polymer, and $z$ is the penetrant compressibility [18]. The isosteric heat of sorption represents the enthalpy of sorption at a fixed concentration [18]. By calculating $\Delta H_{I}$, the interactions between penetrants and polymer segments can be examined. $\Delta H_{I}$ is a measure of the average difference in enthalpy between a molecule in the gas phase and in the sorbed state at a constant penetrant concentration in the polymer. Due to dual-mode effects, as concentration is increased, $\Delta H_{I}$ initially becomes more exothermic and then becomes more endothermic at 
higher concentrations [20]. Furthermore, this analysis can be performed independent of any specific model, such as the dual mode model.

\section{Experimental}

\subsection{Materials}

The diamine monomer, 3,3'-dihydroxy-4,4'-diamino-biphenyl (HAB, Wakayama Seika Kyogo Co., Wakayama, Japan), was covered with aluminum foil to shield it from light and heated under vacuum to $60{ }^{\circ} \mathrm{C}$ overnight before use. The dianhydride monomer, 2,2'-bis-(3,4dicarboxyphenyl) hexafluoropropane dianhydride (6FDA, Alfa Aesar, Ward Hill, MA, USA), was heated to $200{ }^{\circ} \mathrm{C}$ for 6 hours under $-10 \mathrm{inHg}$ of vacuum before being cooled to $120{ }^{\circ} \mathrm{C}$ under full vacuum overnight. Acetic anhydride (AA, 99.5\%, Sigma Aldrich, St. Louis, MO, USA), pyridine ( $\geq 99.9 \%$, Sigma Aldrich, St. Louis, MO, USA), and anhydrous 1-methyl-2pyrrolidinone (NMP, Sigma Aldrich, St. Louis, MO, USA) were used as received. Nitrogen, methane, and carbon dioxide (UHP grade) were obtained from Airgas (Radnor, PA, USA).

\subsection{Synthesis}

The precursor polyimide used in this study was synthesized via chemical imidization as described previously [21]. For a typical synthesis, HAB (19.9 mmol) was added to a threenecked flask equipped with a mechanical stirrer and allowed to dissolve under nitrogen in anhydrous NMP. Next, 6FDA $(20.0 \mathrm{mmol})$ was added along with more NMP to make a $0.15 \mathrm{~g}$ solids per $\mathrm{cm}^{3}$ NMP solution. The flask was then placed in an ice bath, and the monomers were allowed to react for 24 hours. The resulting poly(amic acid) was imidized by adding 8 mol of acetic anhydride and $8 \mathrm{~mol}$ of pyridine per mole of $\mathrm{HAB}$ followed by further dilution with anhydrous NMP to make a $0.08 \mathrm{~g}$ (6FDA, HAB, AA, pyridine) per $\mathrm{cm}^{3}$ NMP solution. The 
solution was stirred under $\mathrm{N}_{2}$ for a further 24 hours. Finally, the reaction flask was equipped with a condenser, and the solution was heated to $60{ }^{\circ} \mathrm{C}$ for one hour to drive the reaction to completion.

The final HAB-6FDA polymer was further diluted with NMP to obtain a $5 \%(\mathrm{w} / \mathrm{v})$ solution before precipitating the solution in a blender containing methanol (VWR, Radnor, PA, USA). Precipitated fibers were filtered and washed with methanol in a Büchner funnel before being placed in a stirred methanol bath for two consecutive 24-hour extraction steps. Fresh methanol was used for each extraction step. The light brown polymer fibers were dried under vacuum for 24 hours at $80{ }^{\circ} \mathrm{C}, 24$ hours at $120^{\circ} \mathrm{C}$, and 48 hours at $200{ }^{\circ} \mathrm{C}$. The ${ }^{1} \mathrm{H}$ NMR and FTIR spectra were consistent with the expected polyimide structure (cf., Figures S1, S2, and S3 in the supplementary materials).

\subsection{Film Preparation}

Approximately $1 \mathrm{~g}$ of HAB-6FDA was dissolved in $N, N$-dimethylacetamide (DMAc, Sigma Aldrich) with stirring to make a $2 \%(\mathrm{w} / \mathrm{w})$ solution. The solution was filtered through a $5.0 \mu \mathrm{m}$ Millex-LS PTFE filter (EMD Millipore; Billerica, MA, USA) into a glass ring silicone caulked to a clean glass plate. The solution and plate were placed on a level surface in a vacuum oven. The oven was partially evacuated to $-25 \mathrm{inHg}$, after which the oven was purged three times with dry air pulled into the oven through a Drierite column (W. A. Hammond DRIERITE Co., Xenia, $\mathrm{OH}, \mathrm{USA})$. The solution was then allowed to evaporate slowly at $80{ }^{\circ} \mathrm{C}$ and $-10 \mathrm{inHg}$ for 24 hours. The films were then peeled off the glass plate and placed between two glass plates with spacers and dried at $200{ }^{\circ} \mathrm{C}$ overnight under full vacuum, resulting in approximately $35 \mu \mathrm{m}$ thick

solvent-free films. Solvent removal was verified by thermogravimetric analysis (cf., Figure S4). 
Thickness was measured as an average of several points using a Mitutoyo Digimatic Micrometer (MDC-1" PJ, \#293-340, Mitutoyo America Corporation, Aurora, IL).

\subsection{TR conversion}

Polyimide films were thermally rearranged to their corresponding polybenzoxazole (PBO) structures (cf., Figure S1 in the supplementary materials) in a Carbolite Split-Tube Furnace (Carbolite, Watertown, WI, USA). Solvent-free films were weighed and sandwiched between ceramic plates with spacers to allow for film contraction during rearrangement. The temperature was raised to $300{ }^{\circ} \mathrm{C}$ at $5{ }^{\circ} \mathrm{C} / \mathrm{min}$ under nitrogen purge $\left(900 \mathrm{~cm}^{3} / \mathrm{min}\right)$. After a dwell period of $1 \mathrm{hr}$, the temperature was raised again to the target thermal rearrangement temperature for a prescribed time before the furnace was allowed to cool down at a maximum rate of 10 ${ }^{\circ} \mathrm{C} / \mathrm{min}$. The thermal rearrangement conditions are summarized in Table 1. The three thermal rearrangement protocols considered in this study were selected to minimize potential thermal degradation at the highest thermal rearrangement temperature at long times and for consistency with our previous studies [14, 21-24] and are denoted by their thermal rearrangement conditions. Each protocol is named TRX-Y where " $\mathrm{X}$ " is the final dwell temperature in ${ }^{\circ} \mathrm{C}$ and " $\mathrm{Y}$ " is the final dwell time. Percent conversion from polyimide to PBO was calculated by mass loss:

$$
\% \text { Conversion }=\frac{\text { Actual mass loss }}{\text { Theoretical mass loss }} \times 100 \%
$$

Eq. 1

where the actual mass loss is the measured difference in mass before and after thermal rearrangement, and the theoretical mass loss is calculated from the polymer repeat unit molecular weights assuming that all ortho-position functional groups undergoing thermal rearrangement do so by rearranging to the polybenzoxazole structure [22]. For samples prepared via this protocol, the extent of conversion varied by $\pm 5 \%$ from sample to sample. 
Table 1: Thermal rearrangement conditions and TR conversion.

\begin{tabular}{cccc}
\hline Sample Name & Conversion time $(\mathrm{min})$ & Dwell Temperature $\left({ }^{\circ} \mathrm{C}\right)$ & \% Conversion \\
\hline HAB-6FDA & -- & -- & -- \\
TR350-1hr & 60 & 350 & 37 \\
TR400-1hr & 60 & 400 & 58 \\
TR450-30m & 30 & 450 & 67 \\
\hline
\end{tabular}

\subsection{Gas Solubility Measurements}

The solubilities of $\mathrm{CH}_{4}$ and $\mathrm{CO}_{2}$ in each sample were determined at temperatures from -10 to $50{ }^{\circ} \mathrm{C}$ using a dual-volume pressure decay apparatus [25]. Approximately $0.5-0.75 \mathrm{~g}$ of polymer was cut into small pieces and stacked in the sample cell. The cell was held under vacuum overnight to degas the polymer film, and the system was then brought to the desired measurement temperature. The charge cell, which is separated from the sample cell by a valve, was filled with penetrant gas and allowed to reach thermal equilibrium. Next, the valve was opened briefly to allow gas to flow from the charge cell into the sample cell. The pressure in the sample cell decayed as gas sorbed into the polymer. After equilibrium was reached, more gas was introduced into the charge cell, and the experiment was repeated in a stepwise manner to a maximum pressure of approximately $27 \mathrm{~atm}$. The resultant equilibrium pressures, the volumes of the charge chamber, the sample chamber, and the polymer sample (estimated from its mass and density) were used to perform a mole balance at each pressure step using the Soave-RedlichKwong (SRK) equation of state [26] to generate the sorption isotherms [25]. After the sorption isotherm measurement, the sample was again held under vacuum in preparation for the next experiment. To avoid effects of $\mathrm{CO}_{2}$ conditioning [27], fresh samples were used after each $\mathrm{CO}_{2}$ isotherm. 
The solubility of $\mathrm{N}_{2}$ in each sample was measured over a range of temperatures $\left(0{ }^{\circ} \mathrm{C}\right.$ to $50{ }^{\circ} \mathrm{C}$ ) gravimetrically, using a Rubotherm Magnetic Suspension Balance (Rubotherm Präzisionsmeßtechnik GmbH; Bochum, Germany). $\mathrm{N}_{2}$ sorption measurements were performed following the procedure outlined in Ref. [14]. Additionally, a liquid argon trap was used in the gas feed line to remove any condensable impurities. The effect of buoyancy on the resultant gas sorption isotherms was accounted for using a procedure described previously [14]. Pressure decay and magnetic suspension balance methods were previously shown to give reasonable agreement for sparingly soluble gases such as $\mathrm{H}_{2}$ [14]. The $\mathrm{N}_{2}$ sorption data presented here are within $6 \%$ of the $\mathrm{N}_{2}$ sorption at $35^{\circ} \mathrm{C}$ previously reported in these materials [21] except for TR350-1hr, which was $20 \%$ higher here than previously reported. However, for TR350-1hr, thermal rearrangement proceeds at a temperature comparable to the glass transition temperature of HAB-6FDA. Small variations in temperature near the glass transition have a significant effect on the packing structures and free volume distributions in these polymers. The differences in this report compared to previous work should be expected based on the sensitive nature of forming the exact physical packing structure of TR polymers that are formed in this range of temperatures surrounding the glass transition.

\section{Results and discussion}

\subsection{Gas sorption isotherm measurements}

Gas solubility was measured for $\mathrm{N}_{2}, \mathrm{CH}_{4}$, and $\mathrm{CO}_{2}$ in HAB-6FDA and three of its TR analogs. To provide a broader context to these results, additional $\mathrm{H}_{2}$ data from a previous study were included in the analysis [14]. Selected isotherms are presented in the main text, and the complete set of isotherms is reported in Figures S5 and S6 in the Supplementary Material 
section. The uncertainties presented here were calculated by the propagation of errors method [28].

Sorption isotherms for $\mathrm{CH}_{4}$ in the polyimide precursor and TR polymers are shown in Figure 1. Solubility increases with decreasing temperature for all samples in this study. Increasing the temperature from 35 to $50{ }^{\circ} \mathrm{C}$ resulted in the concentration of $\mathrm{CH}_{4}$ at 10 atm in the HAB-6FDA polyimide decreasing from 10.6 to $8.7 \mathrm{~cm}^{3}(\mathrm{STP}) /\left(\mathrm{cm}^{3}\right.$ polymer) (17\% decrease). Decreasing the temperature from 35 to $20{ }^{\circ} \mathrm{C}$ resulted in an increase of $27 \%$ from 10.6 to 13.4 $\mathrm{cm}^{3}(\mathrm{STP}) /\left(\mathrm{cm}^{3}\right.$ polymer). At 27 atm (the highest pressure measured for $\left.\mathrm{CH}_{4}\right)$, concentrations ranged from $15.6\left(\right.$ at $50{ }^{\circ} \mathrm{C}$ ) to $32.5\left(\right.$ at $-10{ }^{\circ} \mathrm{C}$ ) $\mathrm{cm}^{3}(\mathrm{STP}) /\left(\mathrm{cm}^{3}\right.$ polymer). At increasing degrees of TR conversion, solubilities increase for all gases tested, as previously reported [21]. 

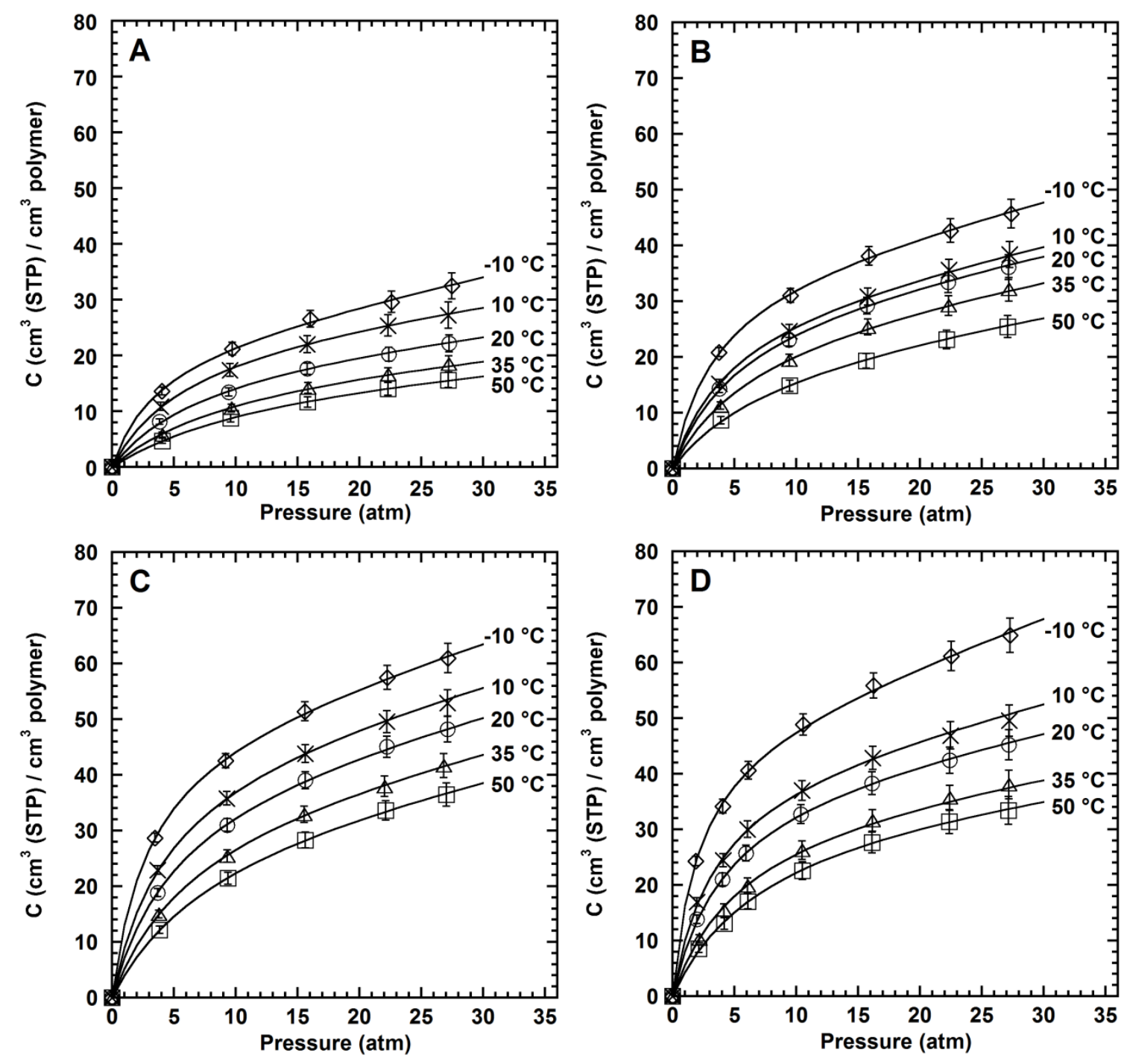

Figure 1: Concentration as a function of pressure of $\mathrm{CH}_{4}$ at $50{ }^{\circ} \mathrm{C}$ (open squares), $35^{\circ} \mathrm{C}$ (open triangles), $20{ }^{\circ} \mathrm{C}$ (open circles), $10{ }^{\circ} \mathrm{C}$ (crosses) and $-10{ }^{\circ} \mathrm{C}$ (open diamonds) in: A) HAB-6FDACI polyimide, B) TR350-1hr, C) TR400-1hr, and D) TR450-30m. The continuous lines are dual mode model fits.

Gas solubilities at 10 atm are presented in Table S1 (Supplementary Material Section) for HAB-6FDA and its TR analogs alongside Matrimid $^{\circledR}$, 6FDA-TAB, PTMSP, and Teflon AF $2400{ }^{\circledR}[7,14,29-31]$ for comparison. As TR conversion increases, solubility increases for all gases with some decrease in solubility selectivity. As expected, solubility increases monotonically with increasing penetrant critical temperature (e.g., in the polyimide, solubility at 10 atm and $35{ }^{\circ} \mathrm{C}$ increased from $0.037 \mathrm{~cm}^{3}$ (STP) / $\left(\mathrm{cm}^{3}\right.$ polymer atm) for $\mathrm{N}_{2}$ to 1.0 for $\mathrm{CH}_{4}$ and 
3.8 for $\mathrm{CO}_{2}$ ). Gas solubilities in HAB-6FDA polyimide are close to those in Matrimid ${ }^{\circledR}$ [30] with similar (if slightly higher) solubilities and correspondingly lower solubility selectivities. In general, solubility selectivities decrease as TR conversion increases.

\subsection{Effect of temperature on gas solubility}

The temperature dependence of gas solubility coefficients in each of the samples is presented in Figure 2. $S$ increased with increasing TR conversion, coinciding with an increase in FFV with TR conversion (as discussed further below). At $35{ }^{\circ} \mathrm{C}$, increases in solubility with TR conversion are similar to those reported by Smith et al. [21], with solubility increasing roughly 23 times the original value. This increase in solubility is ascribed, in part, to an increase in nonequilibrium free volume in the TR polymer structure [21]. For all species, solubility increases as temperature decreases and follows Arrhenius-like behavior, consistent with the behavior observed by Kim et al. in TR- $\beta$-polymers [13]. For each sample, $\mathrm{H}_{2}$ solubility was approximately $70 \%$ higher at $-10{ }^{\circ} \mathrm{C}$ than at $50{ }^{\circ} \mathrm{C} . \mathrm{N}_{2}, \mathrm{CH}_{4}$, and $\mathrm{CO}_{2}$ solubilities were approximately $100 \%$ higher over the same range of temperatures. 

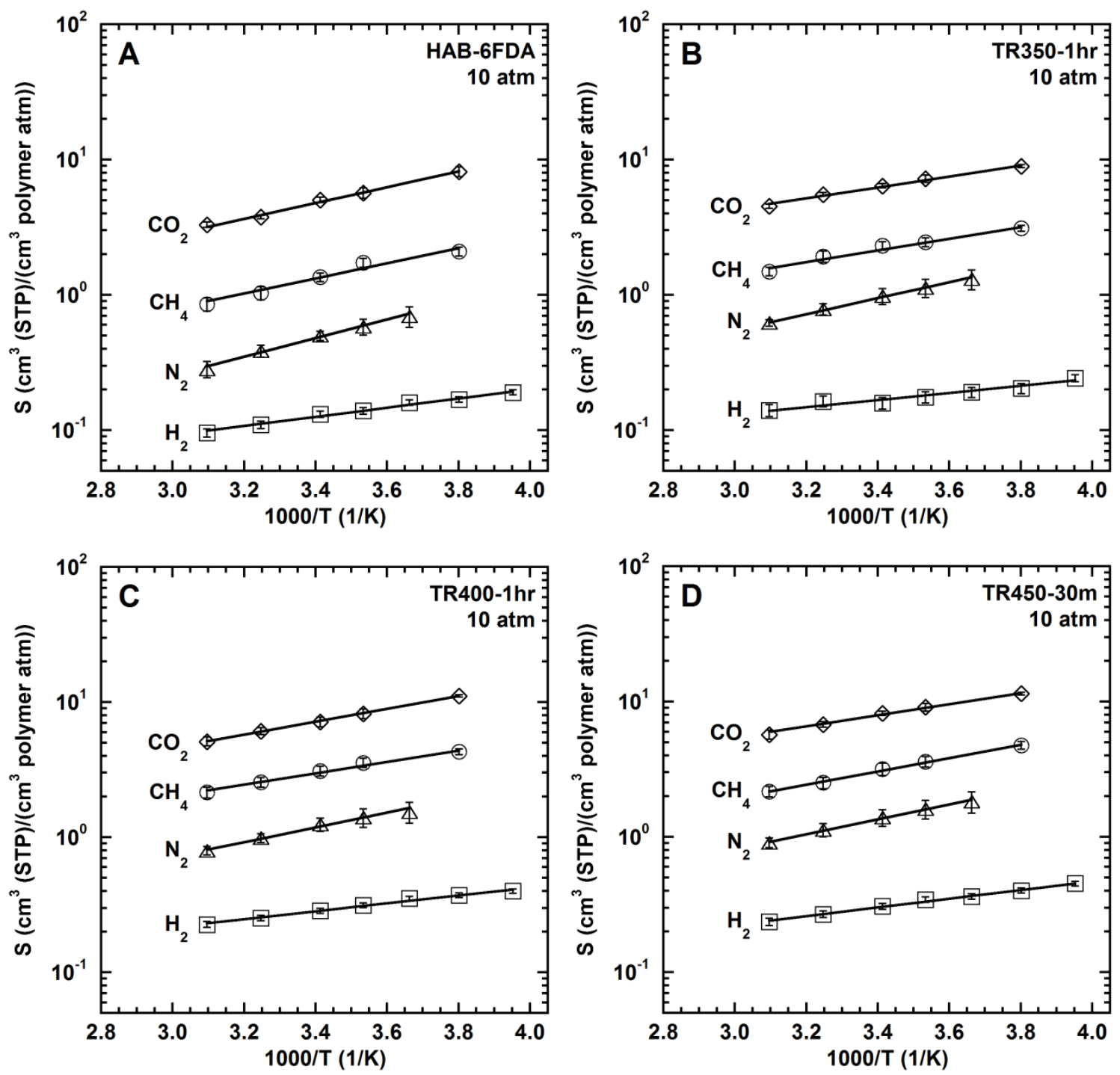

Figure 2: Solubilities at $10 \mathrm{~atm}$ for $\mathrm{CO}_{2}, \mathrm{CH}_{4}, \mathrm{~N}_{2}$, and $\mathrm{H}_{2}$ at multiple temperatures for: A) $\mathrm{HAB}$ 6FDA Polyimide, B) TR350-1hr, C) TR400-1hr, and D) TR450-30m. $\mathrm{H}_{2}$ data are from Smith et al. [14].

In Figure 3, the $\mathrm{CO}_{2}$ sorption coefficient is presented at multiple temperatures for a number of rubbery and glassy polymers, including HAB-6FDA polyimide and its TR450-30m analogue. For PDMS, since it is a rubbery polymer, there is no contribution to $S$ from the Langmuir sorption mode, so gas solubility is lower than in the glassy polymers in Figure 3 [32]. HAB-6FDA and its TR polymer analogs have temperature-dependent sorption behavior similar 
to that of other high free volume, hexafluoroisopropylidene $(6 \mathrm{~F})$-containing polymers such as 6FDA-TAB [33].

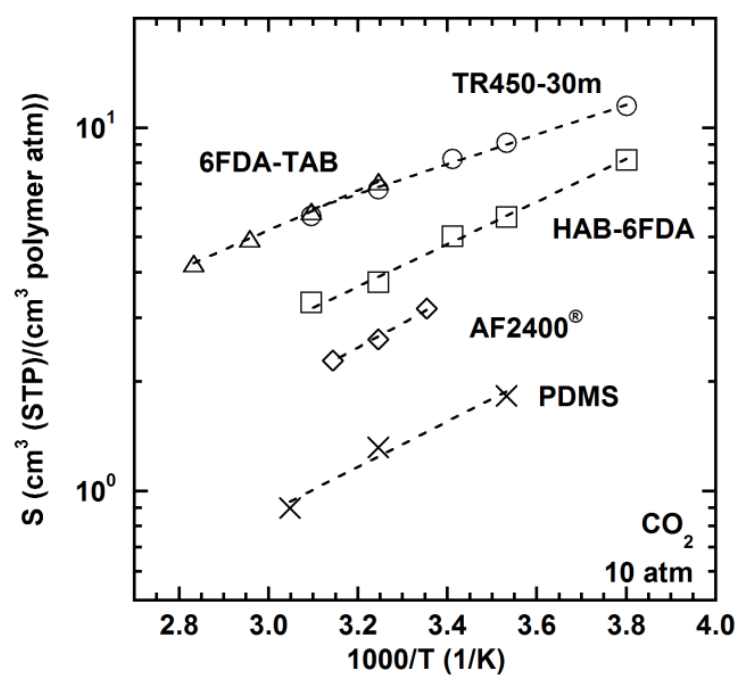

Figure 3: Solubility of $\mathrm{CO}_{2}$ at $10 \mathrm{~atm}$ in HAB-6FDA polyimide (open squares) and TR450-30m (open circles), 6FDA-TAB (open triangles) [33], AF2400 ${ }^{\circledR}$ (open diamonds) [7], and PDMS (crosses) [34].

The slopes of the lines in Figure 2 may be used to calculate the enthalpies of sorption at $10 \mathrm{~atm}$ (cf., Eq. 1). The slopes of $\ln S$ versus $1 / T$ change relatively little with TR conversion, with $\mathrm{CO}_{2}$ exhibiting the most significant variation. Values of $\Delta H_{S}$ for each gas and polymer at $10 \mathrm{~atm}$ are presented in Table 2 , and $R^{2}$ values are presented in Table S3. For many polymers, enthalpies of sorption become more exothermic with increasing penetrant $T_{c}$ (i.e., endothermicity increases in the following order: $\mathrm{CO}_{2}<\mathrm{CH}_{4}<\mathrm{N}_{2}<\mathrm{H}_{2}$ ) [17]. However, HAB6FDA and its TR polymers exhibit an unusual order of enthalpies of sorption $\left(\mathrm{N}_{2}<\mathrm{CH}_{4} \approx \mathrm{CO}_{2}<\right.$ $\mathrm{H}_{2}$ ). This trend has been observed previously in high FFV materials such as 6FDA-TAB [33], which observed the order $\mathrm{O}_{2}<\mathrm{N}_{2}<\mathrm{CH}_{4}<\mathrm{CO}_{2}$, and PIM-1, where $\mathrm{O}_{2}$ sorption was more exothermic than for $\mathrm{CO}_{2}$ at 10 atm [35]. Several factors are often used to rationalize this behavior. First, in the dual mode model, while $b$ can have a strong temperature dependence, the 
temperature dependence of $b /(1+b p)$ is weaker and reduces the magnitude of the Langmuir contribution to the enthalpy of sorption. Additionally, $C_{H}^{\prime}$ typically is less temperaturedependent than $b$. Zimmerman and Koros found that, in polymers with large, relatively temperature-independent values of $C_{H}^{\prime}$, the order of enthalpies of sorption can be affected by these factors [33]. Finally, polymer-penetrant interactions could also influence enthalpies of sorption. However, a theoretical analysis of gas sorption in HAB-6FDA and its TR analogues was recently reported [36]. The polymer-penetrant binary interaction parameters calculated in the study by Galizia et al. were not large, which indicates that polymer-penetrant interactions are minimal.

Table 2: Enthalpies of sorption at $10 \mathrm{~atm}$.

\begin{tabular}{|c|c|c|c|c|c|c|}
\hline & \multirow{2}{*}{$\begin{array}{c}\% \\
\text { Conversion }\end{array}$} & \multicolumn{4}{|c|}{$\Delta H_{S}(\mathrm{~kJ} / \mathrm{mol})$} & \multirow{2}{*}{ Ref. } \\
\hline & & $\mathrm{H}_{2}$ & $\mathrm{~N}_{2}$ & $\mathrm{CH}_{4}$ & $\mathrm{CO}_{2}$ & \\
\hline$T_{c}(\mathrm{~K})$ & & 33.2 & 126.2 & 190.6 & 304.2 & {$[17]$} \\
\hline HAB-6FDA & 0 & $-6.5 \pm 0.6$ & $-13 \pm 2$ & $-11 \pm 1$ & $-11 \pm 1$ & \\
\hline TR350-1hr & 37 & $-5.0 \pm 0.9$ & $-11 \pm 2$ & $-8.2 \pm 0.9$ & $-7.7 \pm 0.5$ & $\mathrm{H}_{2}$ from [14]; \\
\hline TR400-1hr & 58 & $-5.6 \pm 0.5$ & $-10 \pm 2$ & $-8 \pm 1$ & $-9.1 \pm 0.6$ & this study \\
\hline TR450-30m & 67 & $-6.1 \pm 0.6$ & $-11 \pm 2$ & $-9 \pm 1$ & $-8 \pm 1$ & \\
\hline 6FDA-TAB & -- & -- & -11.7 & -11.7 & -10.5 & [33] \\
\hline 6FDA-6FpDA ${ }^{1}$ & -- & -- & -13 & -14.6 & -15 & {$[6]$} \\
\hline PIM-1 & -- & -- & -8.6 & -11.2 & -10.4 & {$[35]$} \\
\hline
\end{tabular}

${ }^{1}$ Data at 5 atm.

As TR conversion increases, free volume increases [8, 21, 23]. As a result of higher free volume, $S$ increases for all gases with increasing TR conversion due predominantly to a large 
Langmuir site contribution to solubility. Figure 4 presents the effect of TR conversion on $\mathrm{CH}_{4}$ solubility at several temperatures. Solubility increases by a factor of 2-3. Similar increases in $S$ as a function of TR conversion were observed for other gases, with $\mathrm{CO}_{2}$ displaying the smallest increase in solubility, consistent with prior observations that smaller increase in $\mathrm{CO}_{2}$ sorption, as compared to increases in sorption for gases such as $\mathrm{N}_{2}$ and $\mathrm{CH}_{4}$, is a result of the loss of acetate and carbonyl functional groups during thermal rearrangement [21].

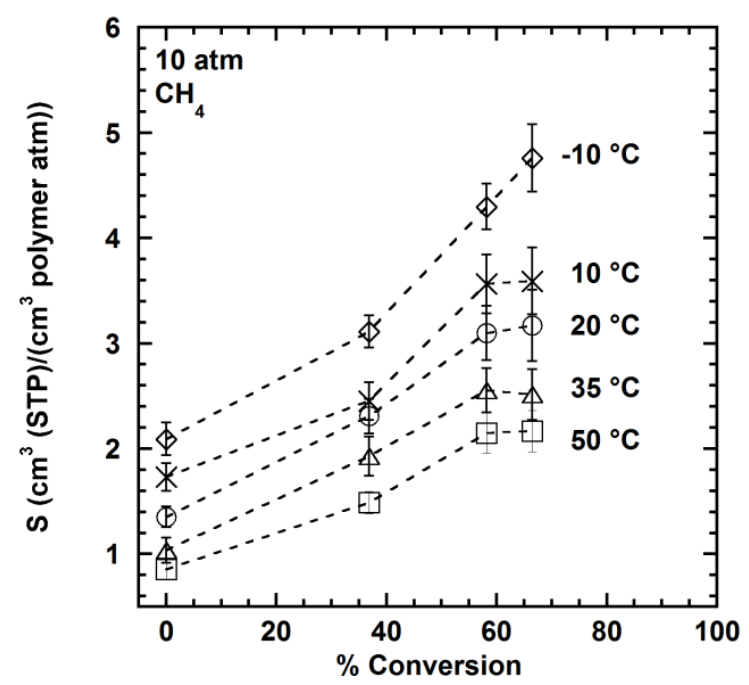

Figure 4: Solubility of $\mathrm{CH}_{4}$ at various temperatures as a function of TR conversion.

While solubility increases with TR conversion, only modest changes in $\Delta H_{S}$ are observed (cf., Table 2). As TR conversion (and FFV) increase, the ratio of Langmuir to Henry's law sorption increases (as will be demonstrated below). Langmuir sorption lacks the energetic penalty of creating gaps between polymer chains to accommodate penetrant molecules that is commonly associated with Henry's Law sorption sites [18], so $\Delta H_{S}$ should become more exothermic as TR conversion increases. As TR conversion increases, $\Delta H_{S}$ does become slightly more exothermic, but the trend is largely within the uncertainty of the measurements. The most significant change in $\Delta H_{S}$ with TR conversion occurs between HAB-6FDA and TR350-1hr. 
$\Delta H_{S}$ decreases in magnitude for all gases for TR350-1hr. At this level of conversion, it is not quantitatively clear what fraction of mass loss comes from solid-state deprotection of the oposition acetate group in the form of acetic acid and what fraction comes from conversion of polyimide to PBO. However, Sanders et al. have predicted that most if not all of the acetate $o$ position groups have been removed and replaced with hydroxyl functionality under these conditions [23]. The presence of hydroxyl functionality on unconverted polymer chain segments can lead to hydrogen bonding and a corresponding increase in the energy penalty associated with Henry's law sorption. On this basis, enthalpies of sorption are expected to be somewhat more exothermic as conversion increases due to fewer remaining hydroxyl groups, less hydrogen bonding, and a lower energy penalty to creating Henry's law sorption sites. However, this effect is small.

While solubilities change as a function of temperature, solubility selectivities remain relatively constant with temperature. If there is no significant difference in $\Delta H_{S}$ for a gas pair (for example, $\mathrm{CO}_{2}$ and $\mathrm{CH}_{4}$ for the TR450-30m sample have enthalpies of sorption of $-8 \pm 1$ and $-9 \pm 1$, respectively), $\Delta H_{S, A}-\Delta H_{S, B}$ is approximately 0 , so the exponential term of Equation 2 is 1. Solubility selectivities for all four samples considered are plotted against inverse temperature in Figure 5. For all four samples at 10 atm, $\Delta H_{S}$ is nearly equivalent for $\mathrm{CO}_{2}$ and $\mathrm{CH}_{4}$, resulting in no substantial changes in $\mathrm{CO}_{2} / \mathrm{CH}_{4}$ selectivity as temperature is varied. 


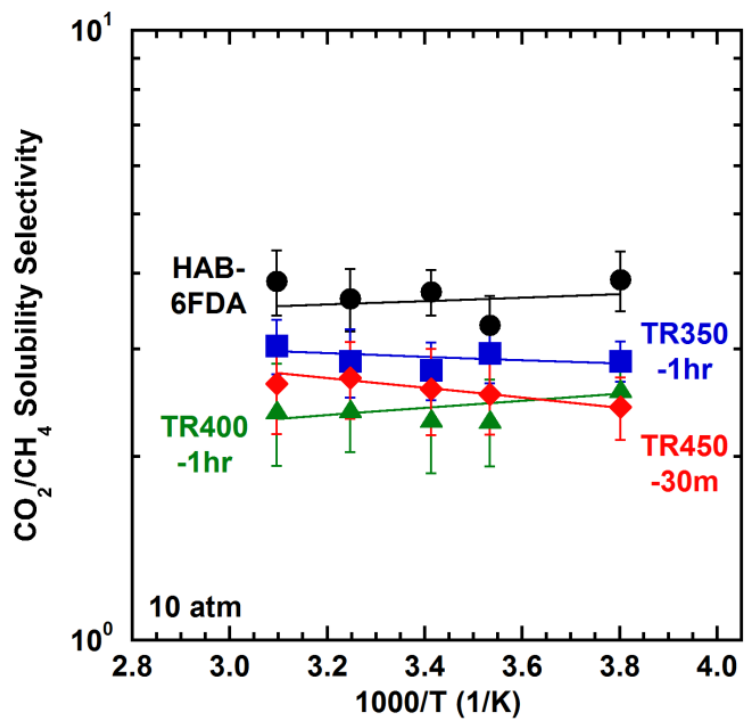

Figure 5: $\mathrm{CO}_{2} / \mathrm{CH}_{4}$ solubility selectivity as a function of inverse temperature for HAB-6FDA (black circles), TR350-1hr (blue squares), TR400-1hr (green triangles), and TR450-1hr (red diamonds). All data in this figure are at an upstream pressure of $10 \mathrm{~atm}$.

The enthalpy of sorption can also be determined as a function of penetrant concentration as indicated in Eq. $7[7,18,20]$. Koros et al. predict a minimum in $\Delta H_{I}$, the isosteric heat of sorption, [18] though this minimum is not always observed and likely occurs outside the range of concentrations (i.e., pressures) considered. Yang et al. studied $\mathrm{H}_{2} \mathrm{O}$ vapor sorption over a wide range of concentrations and observed an initial decrease in $\Delta H_{I}$ for $\mathrm{H}_{2} \mathrm{O}$ vapor in Kapton followed by an increase and asymptotic leveling at higher concentrations [20], which is consistent with the predictions by Koros et al.

Figure 6A presents $\Delta H_{I}$ as a function of penetrant concentration for several penetrants in the TR450-30m sample. The dual mode model was used to interpolate concentration versus pressure isotherms and to calculate $\Delta H_{I}$ according to the method described by Koros et al. [18]. For $\mathrm{N}_{2}$, the Langmuir sites were not yet saturated at the highest concentrations achieved, resulting in no significant change in $\Delta H_{I}$. For $\mathrm{CO}_{2}$ (the most condensable penetrant considered), 
the upturn in $\Delta H_{I}$ above $60 \mathrm{~cm}^{3}$ (STP) $/ \mathrm{cm}^{3}$ polymer is ascribed to filling the Langmuir sites, leading to increasing sorption into Henry's law regions where the endothermic barrier to gas sorption becomes significant. This effect is not observed for the other penetrants in the concentration ranges considered here. $\Delta H_{I}$ for $\mathrm{H}_{2}$ was also calculated but exhibited no concentration dependence. Similar plots for other samples are reported in the Supplementary Materials section (Figure S7) and exhibit similar trends as those presented in Figure 6. $\Delta H_{I}$ represents redistribution of penetrant molecules between Henry's law and Langmuir populations as pressure and temperature are varied to maintain a constant concentration and is not always directly comparable to $\Delta H_{S}$ at a constant pressure.

Except for $\mathrm{H}_{2}$, where solubility was nearly independent of pressure, enthalpies of sorption become less exothermic as gas pressure increased. As gases dissolve into the polymer matrix, there is initially only a minor contribution from Henry's law sorption to overall sorption. At higher concentrations, the endothermic penalty in creating Henry's law sorption sites results in an endothermic shift in $\Delta H_{S}$. An example of this behavior is presented in Figure 6B. 

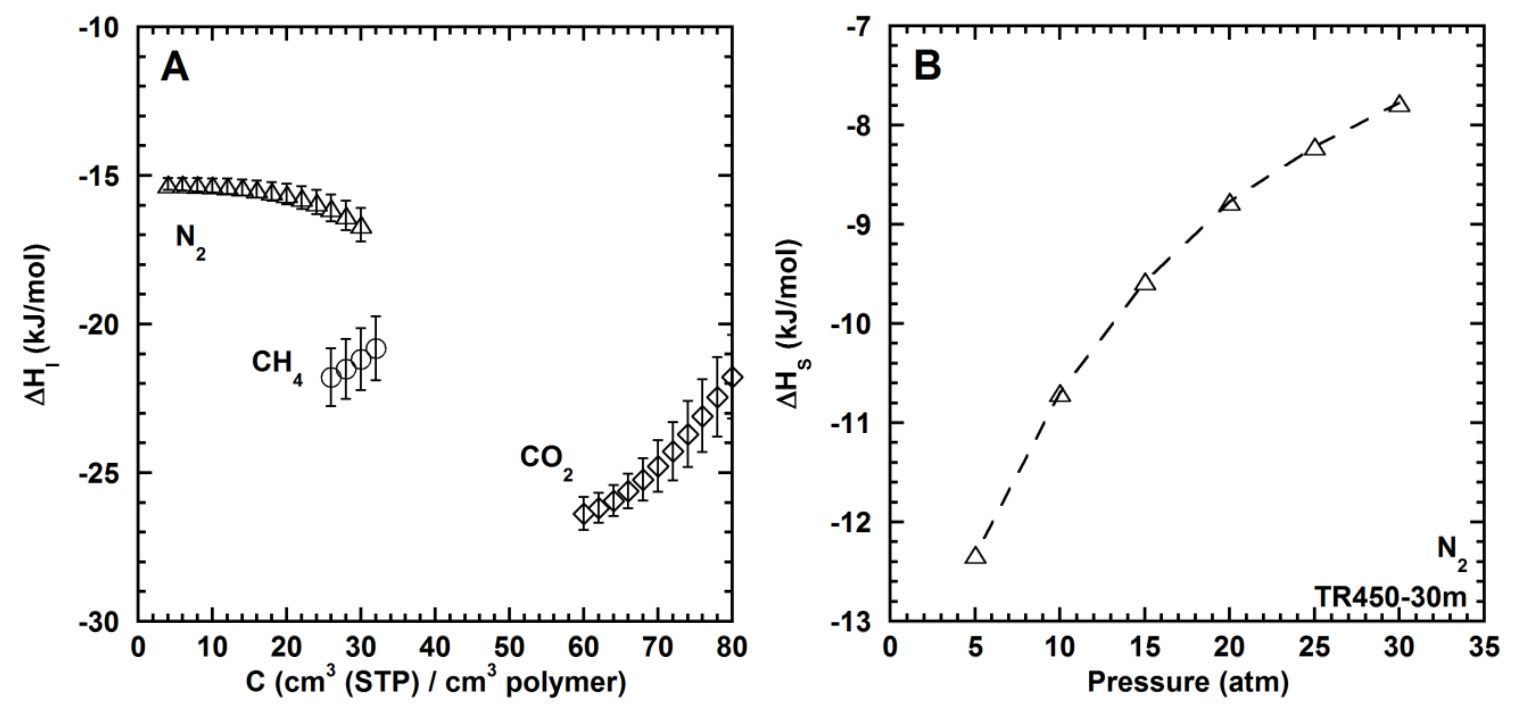

Figure 6: A) Isosteric heat of sorption ( $\Delta H_{I}$ ) for $\mathrm{N}_{2}, \mathrm{CH}_{4}$, and $\mathrm{CO}_{2}$ in TR450-30m. Uncertainties were estimated [28] to be approximately 5-10\%. B) Enthalpy of sorption for $\mathrm{N}_{2}$ in TR450-30m as a function of pressure. The dashed line is a guide for the eye.

\subsection{Dual mode modeling as a function of temperature}

The sorption characteristics of HAB-6FDA and its corresponding TR polymer analogs were further analyzed with the dual mode model. The coupled nature of the model parameters makes unique values difficult to obtain, so one must be cautious in interpreting the parameter values [37]. Furthermore, different regression methods can yield different parameter values [3740]. Predictions and calculations with the dual mode parameters (such as $C$ versus $p$ isotherms and, to a lesser extent, infinite dilution solubilities) are relatively more certain, because perturbations of dual mode parameters moving in opposite directions can result in the same predicted values (e.g., an increase in $C_{H}^{\prime}$ can offset a decrease in $b$, but values of, for example, $S^{\text {inf }}$ in Eq. 6 can remain largely unchanged). However, further calculations based on predicted values can result in propagation of any variations, so the output of dual mode modeling must be considered with caution. The dual mode parameters used in this study were obtained by 
nonlinear least-squares optimization, and the details of the fitting method are reported with the resulting parameters in the Supplementary Materials section.

Infinite dilution solubility coefficients were estimated using Equation 6, and the values exhibit a clear trend with critical temperature for all gases, as shown in Figure 7 and Table S2. The slopes of the logarithm of $S^{\mathrm{inf}}$ against $T_{c}$ are between $0.018-0.019 \mathrm{~K}^{-1}$ for all samples, which is within the range typically observed for both glassy and rubbery polymers [17, 41]. Similar to solubilities at $10 \mathrm{~atm}$, solubilities at infinite dilution increase by a factor of 2-4 with increasing TR conversion.

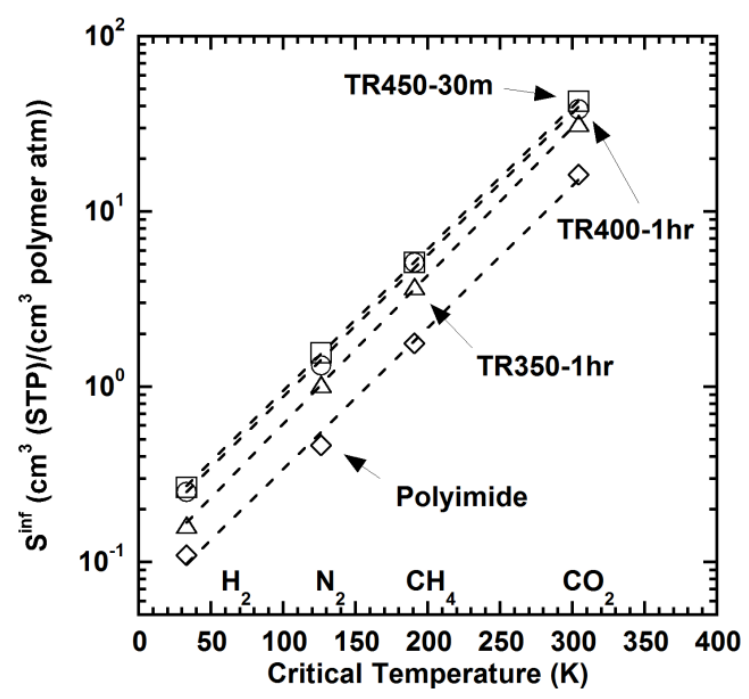

Figure 7: Infinite dilution solubilities of HAB-6FDA polyimide (diamonds), TR350-1hr (triangles), TR400-1hr (circles), and TR450-30m (squares) versus penetrant critical temperature.

Infinite dilution solubility selectivities were calculated and are recorded in Table S2. Infinite dilution solubility selectivities are higher than the corresponding solubility selectivities at 10 atm (cf., Table S1). Similar to 10 atm, infinite dilution solubility selectivities decrease with TR conversion but are significantly higher than those of high free volume materials such as PTMSP and AF2400 ${ }^{\circledR}$ [7, 29]. Robeson and Smith found a slight dependence of solubility selectivity on fractional free volume through analysis of a large data set of solubility data for 
polymers [42]. The higher solubility selectivities observed here, relative to other high free volume materials, could be ascribed to a form of structured free volume elements (such as, for example, hourglass shaped pores [8]) that are more well defined than in other polymers.

\section{Conclusions}

The solubilities of $\mathrm{N}_{2}, \mathrm{CH}_{4}$, and $\mathrm{CO}_{2}$ were measured in $\mathrm{HAB}-6 \mathrm{FDA}$ polyimide and three of its TR analogs at pressures up to 27 atm and temperatures from $-10{ }^{\circ} \mathrm{C}$ to $50{ }^{\circ} \mathrm{C}$. Solubility increased with increasing TR conversion, and enthalpies of sorption became less exothermic upon initial TR conversion. However, further TR conversion had a small impact on the enthalpies of sorption. The endothermic shift in enthalpies of sorption at low levels of TR conversion is hypothesized to be related to the presence of hydrogen bonding, which would tend to increase the energetic penalty to create Henry's law sorption sites, and by cross-links formed during thermal rearrangement. Solubility selectivity decreased with increasing TR conversion but only changed slightly with temperature due to similar enthalpies of sorption for $\mathrm{CH}_{4}$ and $\mathrm{CO}_{2}$. Infinite dilution solubilities correlated well with penetrant critical temperature.

\section{Acknowledgements}

The authors gratefully acknowledge support from the Division of Chemical Sciences, Geosciences, and Biosciences, Office of Basic Energy Sciences of the U.S. Department of Energy (DOE) through Grant DE-FG02-02ER15362. 


\section{References}

[1] R.W. Baker, K. Lokhandwala, Natural gas processing with membranes: an overview, Industrial \& Engineering Chemistry Research, 47 (2008) 2109-2121.

[2] K.A. Berchtold, R.P. Singh, J.S. Young, K.W. Dudeck, Polybenzimidazole composite membranes for high temperature synthesis gas separations, Journal of Membrane Science, 415416 (2012) 265-270.

[3] W.J. Koros, G.K. Fleming, Membrane-based gas separation, Journal of Membrane Science, 83 (1993) 1-80.

[4] T.C. Merkel, M. Zhou, R.W. Baker, Carbon dioxide capture with membranes at an IGCC power plant, Journal of Membrane Science, 389 (2012) 441-450.

[5] W.J. Koros, D.R. Paul, $\mathrm{CO}_{2}$ sorption in poly(ethylene terephthalate) above and below the glass transition, Journal of Polymer Science: Polymer Physics Edition, 16 (1978) 1947-1963.

[6] L.M. Costello, W.J. Koros, Thermally stable polyimide isomers for membrane-based gas separations at elevated temperatures, Journal of Polymer Science Part B: Polymer Physics, 33 (1995) 135-146.

[7] T.C. Merkel, V. Bondar, K. Nagai, B.D. Freeman, Y.P. Yampolskii, Gas sorption, diffusion, and permeation in poly(2,2-bis(trifluoromethyl)-4,5-difluoro-1,3-dioxole-co-tetrafluoroethylene), Macromolecules, 32 (1999) 8427-8440.

[8] H.B. Park, C.H. Jung, Y.M. Lee, A.J. Hill, S.J. Pas, S.T. Mudie, E. Van Wagner, B.D. Freeman, D.J. Cookson, Polymers with cavities tuned for fast selective transport of small molecules and ions, Science, 318 (2007) 254-258.

[9] S.H. Han, J.E. Lee, K.-J. Lee, H.B. Park, Y.M. Lee, Highly gas permeable and microporous polybenzimidazole membrane by thermal rearrangement, Journal of Membrane Science, 357 (2010) 143-151.

[10] Z.P. Smith, K. Czenkusch, S. Wi, K.L. Gleason, G. Hernández, C.M. Doherty, K. Konstas, T.J. Bastow, C. Álvarez, A.J. Hill, A.E. Lozano, D.R. Paul, B.D. Freeman, Investigation of the chemical and morphological structure of thermally rearranged polymers, Polymer, (2014) 1-9.

[11] D.F. Sanders, Z.P. Smith, R. Guo, L.M. Robeson, J.E. McGrath, D.R. Paul, B.D. Freeman, Energy-efficient polymeric gas separation membranes for a sustainable future: A review, Polymer, 54 (2013) 4729-4761.

[12] S.H. Han, H.J. Kwon, K.Y. Kim, J.G. Seong, C.H. Park, S. Kim, C.M. Doherty, A.W. Thornton, A.J. Hill, A.E. Lozano, K.A. Berchtold, Y.M. Lee, Tuning microcavities in thermally rearranged polymer membranes for $\mathrm{CO}_{2}$ capture, Physical Chemistry Chemical Physics, 14 (2012) 4365-4373.

[13] S. Kim, J.G. Seong, Y.S. Do, Y.M. Lee, Gas sorption and transport in thermally rearranged polybenzoxazole membranes derived from polyhydroxylamides, Journal of Membrane Science, 474 (2015) 122-131.

[14] Z.P. Smith, R.R. Tiwari, T.M. Murphy, D.F. Sanders, K.L. Gleason, D.R. Paul, B.D. Freeman, Hydrogen sorption in polymers for membrane applications, Polymer, 54 (2013) 30263037.

[15] K. Ghosal, B.D. Freeman, Gas separation using polymer membranes: an overview, Polymers for Advanced Technologies, 5 (1994) 673-697.

[16] R.S. Prabhakar, T.C. Merkel, B.D. Freeman, T. Imizu, A. Higuchi, Sorption and transport properties of propane and perfluoropropane in poly(dimethylsiloxane) and poly(1-trimethylsilyl1-propyne), Macromolecules, 38 (2005) 1899-1910. 
[17] S. Matteucci, Y. Yampolskii, B.D. Freeman, I. Pinnau, Transport of gases and vapors in glassy and rubbery polymers, in: Y. Yampolskii, I. Pinnau, B. Freeman (Eds.) Materials science of membranes for gas and vapor separation, John Wiley \& Sons, Ltd, Chichester, UK, 2006, pp. $1-47$.

[18] W.J. Koros, D.R. Paul, G.S. Huvard, Energetics of gas sorption in glassy polymers, Polymer, 20 (1979) 956-960.

[19] W.J. Koros, D.R. Paul, Observations concerning the temperature dependence of the langmuir sorption capacity of glassy polymers, Journal of Polymer Science: Polymer Physics Edition, 19 (1981) 1655-1656.

[20] D.K. Yang, W.J. Koros, H.B. Hopfenberg, V.T. Stannett, Sorption and transport studies of water in Kapton polymide. I, Journal of Applied Polymer Science, 30 (1985) 1035-1047.

[21] Z.P. Smith, D.F. Sanders, C.P. Ribeiro, R. Guo, B.D. Freeman, D.R. Paul, J.E. McGrath, S. Swinnea, Gas sorption and characterization of thermally rearranged polyimides based on 3,3'dihydroxy-4,4'-diamino-biphenyl (HAB) and 2,2'-bis-(3,4-dicarboxyphenyl) hexafluoropropane dianhydride (6FDA), Journal of Membrane Science, 415-416 (2012) 558-567.

[22] D.F. Sanders, Z.P. Smith, C.P. Ribeiro, R. Guo, J.E. McGrath, D.R. Paul, B.D. Freeman, Gas permeability, diffusivity, and free volume of thermally rearranged polymers based on 3,3'dihydroxy-4,4'-diamino-biphenyl (HAB) and 2,2'-bis-(3,4-dicarboxyphenyl) hexafluoropropane dianhydride (6FDA), Journal of Membrane Science, 409-410 (2012) 232-241.

[23] D.F. Sanders, R. Guo, Z.P. Smith, Q. Liu, K.A. Stevens, J.E. McGrath, D.R. Paul, B.D. Freeman, Influence of polyimide precursor synthesis route and ortho-position functional group on thermally rearranged (TR) polymer properties: Conversion and free volume, Polymer, 55 (2014) 1636-1647.

[24] D.F. Sanders, R. Guo, Z.P. Smith, K.A. Stevens, Q. Liu, J.E. McGrath, D.R. Paul, B.D. Freeman, Influence of polyimide precursor synthesis route and ortho-position functional group on thermally rearranged (TR) polymer properties: Pure gas permeability and selectivity, Journal of Membrane Science, 463 (2014) 73-81.

[25] H. Czichos, T. Saito, L. Smith, Springer handbook of materials measurement methods, Springer Verlag, 2006.

[26] J.M. Smith, H.C. Van Ness, M.M. Abbott, Introduction to chemical engineering thermodynamics, McGraw-Hill, Boston, 2005.

[27] A.G. Wonders, D.R. Paul, Effect of $\mathrm{CO}_{2}$ exposure history on sorption and transport in polycarbonate, Journal of Membrane Science, 5 (1979) 63-75.

[28] P.R. Bevington, D.K. Robinson, Data reduction and error analysis for the physical sciences, McGraw Hill, Boston, 2003.

[29] T.C. Merkel, V. Bondar, K. Nagai, B.D. Freeman, Sorption and transport of hydrocarbon and perfluorocarbon gases in poly(1-trimethylsilyl-1-propyne), Journal of Polymer Science Part B: Polymer Physics, 38 (2000) 273-296.

[30] T.T. Moore, W.J. Koros, Gas sorption in polymers, molecular sieves, and mixed matrix membranes, Journal of Applied Polymer Science, 104 (2007) 4053-4059.

[31] C.M. Zimmerman, W.J. Koros, Polypyrrolones for membrane gas separations. I. Structural comparison of gas transport and sorption properties, Journal of Polymer Science Part B: Polymer Physics, 37 (1999) 1235-1249.

[32] T.C. Merkel, V.I. Bondar, K. Nagai, B.D. Freeman, I. Pinnau, Gas sorption, diffusion, and permeation in poly(dimethylsiloxane), Journal of Polymer Science Part B: Polymer Physics, 38 (2000) 415-434. 
[33] C.M. Zimmerman, W.J. Koros, Polypyrrolones for membrane gas separations. II. Activation energies and heats of sorption, Journal of Polymer Science Part B: Polymer Physics, 37 (1999) 1251-1265.

[34] V.M. Shah, B.J. Hardy, S.A. Stern, Solubility of carbon dioxide, methane, and propane in silicone polymers: Effect of polymer side chains, Journal of Polymer Science Part B: Polymer Physics, 24 (1986) 2033-2047.

[35] P. Li, T.S. Chung, D.R. Paul, Temperature dependence of gas sorption and permeation in PIM-1, Journal of Membrane Science, 450 (2014) 380-388.

[36] M. Galizia, K.A. Stevens, Z.P. Smith, D.R. Paul, B.D. Freeman, Nonequilibrium Lattice Fluid Modeling of Gas Solubility in HAB-6FDA Polyimide and Its Thermally Rearranged Analogues, Macromolecules, 49 (2016) 8768-8779.

[37] W.J. Koros, A.H. Chan, D.R. Paul, Sorption and transport of various gases in polycarbonate, Journal of Membrane Science, 2 (1977) 165-190.

[38] E.S. Sanders, High-pressure sorption of pure and mixed gases in glassy polymers (Ph.D. Dissertation), North Carolina State University, Raleigh, 1983.

[39] K.L. Gleason, Z.P. Smith, Q. Liu, D.R. Paul, B.D. Freeman, Pure- and mixed-gas permeation of $\mathrm{CO}_{2}$ and $\mathrm{CH}_{4}$ in thermally rearranged polymers based on 3,3'-dihydroxy-4,4'diamino-biphenyl (HAB) and 2,2'-bis-(3,4-dicarboxyphenyl) hexafluoropropane dianhydride (6FDA), Journal of Membrane Science, 475 (2015) 204-214.

[40] V.I. Bondar, Y. Kamiya, Y.P. Yampol'skii, On pressure dependence of the parameters of the dual-mode sorption model, Journal of Polymer Science Part B: Polymer Physics, 34 (1996) 369378.

[41] R.S. Prabhakar, B.D. Freeman, I. Roman, Gas and vapor sorption and permeation in poly(2,2,4-trifluoro-5-trifluoromethoxy-1,3-dioxole-co-tetrafluoroethylene), Macromolecules, 37 (2004) 7688-7697.

[42] L.M. Robeson, Z.P. Smith, B.D. Freeman, D.R. Paul, Contributions of diffusion and solubility selectivity to the upper bound analysis for glassy gas separation membranes, Journal of Membrane Science, 453 (2014) 71-83. 